\title{
Deficiência intelectual: análise da produção científica com base no modelo biomédico e modelo social da deficiência
}

\author{
Intellectual deficiency: analysis of scientific production \\ based on biomedical model and social model of deficiency
}

Andreia Silva da Mata ${ }^{1}$

\begin{abstract}
Resumo:
O presente estudo teve como objetivo realizar uma pesquisa bibliográficadocumental a partir de artigos disponíveis na base de dados do Scielo. Para a seleção desses artigos foram utilizadas sete palavras-chave que permitiram identificar as pesquisas sobre as pessoas com deficiência intelectual. A partir desta seleção realizou-se uma análise qualitativa dos resumos e dos objetivos destes artigos separando-os com base na fundamentação teórica do modelo conceitual sobre a deficiência intelectual utilizados nesta pesquisa, a saber: o modelo biomédico e o modelo social da deficiência. Os resultados indicaram a predominância de pesquisas na vertente biomédica, além da predominância de estudos realizados com crianças com deficiência intelectual.
\end{abstract}

Palavras-chave: Modelo biomédico. Modelo social da deficiência. Deficiência intelectual.

\begin{abstract}
:
The present study aimed to perform a bibliographic-documentary research from articles available in the Scielo database. For the selection of these articles, seven key words were used to identify research on people with intellectual disabilities. From this selection, a qualitative analysis of the abstracts and objectives of these articles was carried out, separating them based on the theoretical basis of the conceptual model on the intellectual disability used in this research, namely the biomedical model and the social model of the disability. The results indicated the predominance of biomedical research, as well as the predominance of studies with children with intellectual disabilities.
\end{abstract}

Keywords: Biomedical model. Social model of disability. Intellectual disability.

\footnotetext{
${ }^{1}$ Professora do curso de pós-graduação em Psicopedagogia e Neurociências do Centro Universitário Campo Limpo Paulista - Unifaccamp.
} 


\section{INTRODUÇÃO}

A natureza humana pode ser avaliada e pesquisada em seus mais diversos sentidos e espectros. A partir da premissa de que o homem é um ser "biopsicossocial" e por ser este um objeto demasiadamente complexo para ser considerado em um único estudo científico, muitas pesquisas têm sido realizadas tomando como objeto apenas uma de suas vertentes, quer seja a biológica, a psicológica ou mesmo a social.

A vertente biológica busca explicar os diversos aspectos relativos ao funcionamento do organismo humano. Os resultados de seus estudos, que são realizados com base em métodos de pesquisas predominantemente quantitativo, permitem realizar comparações que podem tornar-se referência para determinar padrões de normalidade ou patológicos para a espécie humana. As investigações científicas realizadas nesta vertente caracterizamse como pertencentes à área biomédica, não tendo como desconsiderar a sua relevância, tanto nos aspectos metodológicos de suas pesquisas, quanto nos progressos obtidos a partir de suas descobertas.

Inclusive, nota-se a notória influência dessas descobertas para o embasamento de outras ciências tal como ocorre, por exemplo, na vertente da ciência psicológica, que podem ser observado em suas abordagens da psicologia behaviorista e mais recentemente na psicologia comportamental. Essas abordagens da ciência psicológica se utilizam dos fundamentos biológicos estabelecidos pelas pesquisas na área biomédica para elaborar diversos estudos sobre o comportamento humano, tomando como paradigma a relação organismo e ambiente. As pesquisas nesta área do conhecimento adotam orientações metodológicas muito similares à área biomédica, com o uso dos modelos quantitativos, estruturando delineamentos de natureza semi-experimental, correlacional, entre outros, sempre com o emprego da estatística como elemento crucial para medir as relações humanas, garantindo à estas aferições algum grau de confiabilidade.

Enquanto isso, as áreas representantes das ciências sociais buscam explicar como as relações culturais geradas a partir do imaginário social, das 
relações de poder entre os membros de uma determinada sociedade, entre outros fatores socialmente produzidos, exercem influência sobre o indivíduo, conferindo a este, mudanças e alterações tão singulares. Nesse sentido, para as ciências sociais, o homem é visto como um ser coletivo, que surge e interage a partir das forças de uma sociedade que se encontra em constante mudança.

A partir desta breve consideração sobre algumas vertentes da ciência que colaboram substancialmente na compreensão do fenômeno humano em todas as suas perspectivas, quer seja orgânica, quer seja histórica, quer seja psíquica, o presente trabalho teve como proposta realizar um levantamento das pesquisas científicas realizadas no Brasil sobre a pessoa com deficiência intelectual. O objetivo foi o de comparar a natureza das pesquisas encontradas sobre o tema proposto com os paradigmas da deficiência no modelo biomédico e do modelo social da deficiência. Para se atingir tal objetivo foi realizado buscas de artigos científicos no site da Scielo, utilizando-se de palavras-chave como critério de filtro, cujos passos metodológicos são apresentados no método. Na sequência serão apresentadas as definições sobre deficiência intelectual e uma breve apresentação do modelo biomédico da deficiência e do modelo social da deficiência que serviram como embasamento teórico para a análise dos artigos selecionados.

\section{Deficiência Intelectual}

As deficiências constituem um campo de pesquisa pouco explorado em nosso país. No mundo, cerca de 1,7 bilhões de pessoas tem alguma restrição que as classifica como deficiente. De acordo com os dados do Censo demográfico (IBGE, 2010), quase 46 milhões $(23,9 \%)$ da população brasileira foi acometida por algum tipo de deficiência, física, sensorial, mental e intelectual. Deste total 2.617.025 (1,37\%) da população brasileira são pessoas com deficiência intelectual, de acordo com o último Censo demográfico brasileiro (IBGE, 2010). 
Historicamente foram utilizadas muitas terminologias para nomear as pessoas com deficiência intelectual. De acordo com o levantamento histórico-cultural realizado por Dias e Lopes de Oliveira (2013), as concepções passaram por transformações ao longo do tempo em função das concepções de mundo vigentes e das dinâmicas culturais de cada época, que geraram implicações no ordenamento jurídico, social e científico. Por conseguinte, essas concepções nortearam as práticas sociais no campo da educação e da saúde. As autoras destacam que a deficiência intelectual se constituiu, ora por influência de concepções inatistas, ora por concepções ambientalistas, tendo a partir do século XX interpretações com base na perspectiva dialógica e cultural, ancoradas nas ideias de Vigotski.

Dentre os termos utilizados Dias e Lopes de Oliveira (2013) destacam a existência de uma relação bidirecional, com o objetivo de identificar a deficiência ou a pessoa. Dentre os termos utilizados para definir a deficiência intelectual encontram-se a debilidade mental, subnormalidade mental, oligofrenia, deficiência mental, retardo mental, capacidade diferentes, barreiras na aprendizagem. E para a identificação da pessoa com deficiência, historicamente foram utilizados os termos idiotas, imbecis, tontos, cretinos, dementes, retardados mentais, inválidos, com necessidades educativas especiais, deficientes intelectuais, estúpidos e amentes.

Em alguns casos, os termos empregados à pessoa com deficiência foram ordenados com a finalidade de identificar o grau de sua deficiência. Como exemplo da existência de uma visão classificatória, o trabalho de Antipoff (1981, p. 18) faz referência à classificação dos excepcionais em dois grandes grupos: com predomínio de fatores bio-páticos e os sóciopáticos. Nas pessoas que apresentavam características bio-páticos (hereditários, congênitos e adquiridos) mais evidentes, os déficits na capacidade intelectual eram classificadas em débeis para indicar um grau leve de deficiência, imbecis para indicar que se tratava de pessoas débeis educáveis, e, os idiotas que classificava as pessoas débeis em grau profundo. Os fatores sócio-páticos referiam-se a predominância da carência de estímulos ambientais e educacionais (ANTIPOFF, 1981). 
Quando a discussão versa sobre as deficiências, quase sempre este termo é pensado a partir das definições médicas, contidas nos manuais de saúde mental, organizados por associações médicas internacionais. A deficiência intelectual possui uma definição médica apresentada no manual diagnóstico e estatístico de transtornos mentais- DSM-5 (2014) organizado pela American Psychiatry Association (APA), que traz a seguinte definição:

Deficiência intelectual (transtorno do desenvolvimento intelectual) é um transtorno com início no período do desenvolvimento que inclui déficits funcionais, tanto intelectuais quanto adaptativos, nos domínios conceitual, social e prático. Os três critérios a seguir devem ser preenchidos: a) déficits em funções intelectuais como raciocínio, solução de problemas, planejamento, pensamento abstrato, juízo, aprendizagem acadêmica e aprendizagem pela experiência confirmados tanto pela avaliação clínica quanto por testes de inteligência padronizados e individualizados; b) déficits em funções adaptativas que resultam em fracasso para atingir padrões de desenvolvimento e socioculturais em relação a independência pessoal e responsabilidade social. Sem apoio continuado, os déficits de adaptação limitam o funcionamento em uma ou mais atividades diárias, como comunicação, participação social e vida independente, e em múltiplos ambientes, como em casa, na escola, no local de trabalho e na comunidade; c) início dos déficits intelectuais e adaptativos durante o período do desenvolvimento. (AMERICAN PSYCHIATRY ASSOCIATION, 2014, p. 33)

A deficiência intelectual não apresenta características idênticas, é classificada em função da gravidade do quadro em: grau leve, grau moderado, grau grave e grau profundo. A gravidade é considerada a partir da avaliação da capacidade adaptativa do indivíduo, levando-se em consideração o nível de apoio de que a pessoa necessita para realizar as tarefas da vida diária e laboral. Nesta classificação não deve ser considerado os escores obtidos nos testes de inteligência em função da pouca 
confiabilidade desses índices localizados na extremidade inferior de sua variação (AMERICAN PSYCHIATRY ASSOCIATION, 2014).

A American Association on Developmental Desabilities (AAIDD) (SCHALOCK et al, 2010) elaborou o conceito de deficiência intelectual relacionando a existência, em um mesmo organismo, de limitações importantes no funcionamento intelectual do indivíduo e prejuízos em três áreas adaptativas: as habilidades conceituais, sociais e práticas relativas à vida diária e a adaptação da pessoa às demandas sociais, considerando o seu ambiente social. Dias e Lopes de Oliveira (2013) destacam a existência de diferenças na compreensão social da deficiência intelectual, quando esta é comparada as outras formas conhecidas de deficiências. Essas autoras descrevem que:

A deficiência intelectual encontra-se em situação peculiar, tanto devido à invisibilidade inerente ao indivíduo não sindrômico, como pelas representações sociais dominantes que, ao passo que atribuem à pessoa com deficiência intelectual uma cognição infantil, contribuem para lhes excluir do direito a uma vida autônoma e cidadã. (DIAS E LOPES DE OLIVEIRA, 2013, P. 170).

De acordo com Pessotti (2012) a deficiência intelectual é concebida mais recentemente sob uma perspectiva que ultrapassa os limites orgânicos, incluindo em seu bojo os aspectos culturais e educacionais. Contudo, notase nos conceitos elaborados tanto pela APA como pela AAIDD que os aspectos adaptativos, embora devam considerar os elementos culturais e a exposição do indivíduo aos processos educacionais, mantém em sua constituição a posição do indivíduo avaliado como objeto isolado, cujas limitações são inerentes ao seu organismo.

É evidente que a própria natureza das associações americanas que delinearam e atualizaram o conceito de deficiência intelectual imprimiram ao conceito em questão a visão médica da deficiência, a de um corpo que não atende aos padrões esperados de desempenho intelectual que impeça ou dificulte em algum grau a adaptação da pessoa em seu meio. Toma por base 
os padrões de normalidade, tornando uma pessoa deficiente em grau mais elevado quanto maior for o distanciamento do seu desempenho quando este é comparado aos índices esperados para a idade do indivíduo. Portanto, considera-se que uma pessoa tenha deficiência quando esta se distancia dos padrões de normalidade, tomando o critério da comparabilidade o ponto central desta discussão.

\section{Modelo biomédico da deficiência}

O modelo biomédico da deficiência passou a ser conhecido a partir da década de 60 carregando a díade deficiência x cura. Quanto mais próximo do saudável estivesse à pessoa, maiores seriam as suas chances de exercer seus direitos como cidadã. Ainda, aponta para as limitações como as únicas causas dos processos de exclusão e de discriminação vivenciados pelas pessoas com deficiência, isentando assim a sociedade pelos atos discriminatórios direcionados a essas pessoas (WERNECK, 2004).

Para França (2013), o modelo médico da deficiência é entendido como fruto da incapacidade gerada por um corpo com lesão. Nesta perspectiva, "a deficiência seria a consequência lógica e natural do corpo lesionado", caracterizando a incapacidade física, que pode conferir aos indivíduos diversas desvantagens sociais.

Diniz (2007) sintetiza o modelo médico como sendo o ato de catalogar a deficiência, enquadrando-a dentro de parâmetros biomédicos pré-estabelecidos de incapacidades e impossibilidades com orientação a programas de reabilitação. Para a autora, o conceito de deficiência é complexo, mas quando analisado para além do modelo médico traz à tona a "estrutura social que oprime a pessoa deficiente", comparando com outras formas de opressão, como o sexismo e o racismo. Aponta também a importância de se realizar estudos sobre a deficiência, pois permite levantar e discutir, o que considera como sendo "uma das ideologias mais opressoras de nossa vida social: a que humilha e segrega o corpo deficiente" (DINIZ, 2007, p. 10). A autora acrescenta ainda que a linguagem utilizada para 
definir a deficiência, e suas formas, sempre foi carregada de violência e de eufemismos discriminatórios, dados que permeiam o ideário que a sociedade mantém sobre a pessoa com deficiência.

Tal como apontado por Gesser, Nuerberg e Toneli (2012) o modelo da deficiência pautado no paradigma biomédico imputa ao indivíduo deficiente uma visão de que este apresenta limitações como algo intrínseco ao sujeito.

No entanto, esta perspectiva de análise tem sido objeto de diversos debates há algumas décadas, com proposta de novo campo paradigmático para a compreensão das deficiências.

\section{Modelo social da deficiência}

A discussão sobre a mudança de perspectiva do conceito de deficiência iniciou no Reino Unido em 1960, tendo como precursores os sociólogos e deficientes físicos Paul Hunt, Michael Oliver, Abberley e Vic Finkelstein. A partir de suas vivências em instituições para pessoas com deficiência, buscaram demonstrar que a deficiência era uma característica individual na interação social. Para tanto, empenharam-se na compreensão do fenômeno sociológico da deficiência, partindo do conceito de estigma proposto por Erving Goffman. Fundaram a Liga dos Lesados Físicos Contra a Segregação (UPIAS), que contribuiu substancialmente para uma mudança no debate biomédico sobre deficiência, além de colaborar com pesquisas e definições sobre o modelo social da deficiência (DINIZ, 2007).

Bampi, Guilherme e Alves (2010), discutiram o termo deficiência, a partir do modelo médico e do modelo social, discorrendo sobre as diferenças conceituais entre ambos. Apontam que, para o modelo médico, a deficiência é entendida como uma situação irreversível, configurando uma condição permanente, fato que coloca a pessoa deficiente em uma condição de desvantagem. No modelo social, a deficiência é considerada um fenômeno sociológico e a lesão, que caracteriza a deficiência, configura-se apenas como uma expressão biológica. Ainda, para Bampi, Guilherme e 
Alves (2010, p. 6), "a deficiência não deveria ser entendida como um problema do indivíduo, uma trajetória pessoal, mas como consequência dos arranjos sociais pouco sensíveis à diversidade", visão que contempla atributos do modelo social da deficiência.

Gesser, Nuerberg e Toneli (2012) afirmam que o modelo social da deficiência transpõe o modelo biomédico da deficiência e se insere no campo das humanidades, permitindo a análise e o desenvolvimento interdisciplinar desta área do conhecimento. $\mathrm{O}$ modelo social da deficiência traz em seu bojo a ideia de que a deficiência encontra-se nas ações de segregação da sociedade, que muitas vezes trabalham para a exclusão das pessoas com deficiências.

Gesser, Nuerberg e Toneli (2012) partem do pressuposto de que as pessoas com deficiência sofrem de forma sistemática, discriminações e exclusões sociais em função de seus impedimentos corporais, contudo, esse processo de exclusão reflete na verdade as barreiras atitudinais, físicas e institucionais impostas pela sociedade. Este modelo rompe com as concepções da deficiência que, no modelo biomédico, reduz a sua compreensão apenas a natureza de suas lesões e dos consequentes impedimentos vivenciados pelo corpo e propõe uma nova interpretação conceitual ao incorporar, no modelo já existente, questões de análise sociais e políticas.

A partir das discussões sobre os paradigmas conceituais que buscam definir a deficiência, foram elaboradas algumas definições legais no cenário nacional brasileiro, como a Lei $n^{\circ}$ 13.146/2015 (BRASIL, 2015), elaborada a partir das determinações acordadas no decreto 6.949/2009 (BRASIL, 2009) que trata sobre a "Convenção Internacional Sobre os Direitos da Pessoa com Deficiência" que tomou por base o modelo biomédico para caracterizar o conceito da deficiência e o modelo social para compreender as relações sociais da Pessoa com Deficiência (PcD). Tal iniciativa foi ao encontro do pensamento de (DINIZ, 2007, p. 11): “o ponto de partida das negociações políticas deve ser o novo conceito de deficiência como 
instrumento de justiça social, e não somente como questão familiar ou individual".

Para a autora, a deficiência deve passar a ser uma questão do campo do direito, da justiça social e das políticas de bem-estar, sendo, portanto, um conceito político, indicando a necessidade de considerar a deficiência como uma questão sociológica, para além do saber biomédico.

O que pode ser notado é que a Lei 13.146/2015 (BRASIL, 2015) propõe um entrelaçamento entre dois paradigmas conceituais sobre a deficiência humana e busca estabelecer uma relação harmônica entre ambas, legitimando uma visão dialética e dinâmica entre essas bases conceituais, tornando a pessoa com deficiência o ponto central da compreensão social e do ordenamento jurídico. Esse entrelaçamento pode ser constatado nos $\operatorname{artigos} 2^{\circ}$ e $3^{\circ}$ da referida Lei. $O$ artigo $2^{\circ}$ da lei brasileira trata da caracterização da pessoa com deficiência:

Art. $2^{\circ}$ Considera-se pessoa com deficiência aquela que tem impedimento de longo prazo de natureza física, mental, intelectual ou sensorial, o qual, em interação com uma ou mais barreiras, pode obstruir sua participação plena e efetiva na sociedade em igualdade de condições com as demais pessoas.

Define também em seu artigo $3^{\circ}$ o que deve ser considerado em relação aos termos acessibilidade, desenho universal, tecnologia assistida ou ajuda técnica, tipos de barreiras (urbanísticas, arquitetônicas, de transportes, na comunicação, atitudinais, tecnológicas), entre outros termos empregados para melhor definir as relações da pessoa com deficiência com o seu meio, tomando por base os pressupostos do modelo social de deficiência (GOMES \& LHULLIER, 2017).

A partir das considerações acerca dos paradigmas que envolvem a pessoa com deficiência e em especial a pessoa com deficiência intelectual surgiu a necessidade de realizar uma pesquisa de levantamento para verificar qual das concepções citadas estão norteando as pesquisas científicas realizadas sobre a pessoa com deficiência intelectual no Brasil. 


\section{Método}

Na busca de evidências preliminares sobre qual das concepções sobre a deficiência intelectual permeiam as pesquisas científicas realizadas no Brasil, foi realizada uma busca por artigos científicos na base de dados da Scielo (www.scielo.com), sem restrição de período, adotando sete palavraschave que pudessem se relacionar à pessoa com deficiência intelectual. Para a seleção destas palavras-chave foram utilizados os conceitos relativos à pessoa com deficiência e a própria deficiência intelectual. Após a identificação dos artigos científicos estes foram registrados em uma planilha ordenados por palavra-chave, autor, título e ano de publicação, com eliminação dos artigos em duplicidade. A partir da localização dos artigos e da organização do banco de dados foi realizada a leitura e análise dos resumos e dos títulos apresentados nos artigos com o objetivo de levantar informações pertinentes ao objetivo da pesquisa, tipo de amostra utilizada e principais resultados encontrados. Na sequência, as informações extraídas dos resumos e dos títulos dos respectivos artigos científicos foram analisadas e classificadas em 18 categorias de objetivo de pesquisa, dado que permitiu investigar a natureza das pesquisas quanto à concepção de deficiência que norteou cada estudo. Também foi analisada a produção científica em função da faixa etária da amostra.

\section{Resultados}

A partir dos estudos de textos que tratam sobre deficiência intelectual e da pessoa com deficiência $(\mathrm{PcD})$ intelectual, foram selecionadas sete palavras-chave para a realização de busca de artigos científicos nas bases de dados da Scielo, sem a delimitação de ano. Inicialmente foram localizados 311 artigos, mas após o ordenamento dos materiais encontrados por ordem alfabética do sobrenome do primeiro autor e do título do artigo em uma planilha Excell, houve a exclusão de 9 artigos que estavam em duplicidade, 
totalizando assim 302 artigos para a realização de outras análises, conforme o objetivos deste estudos. A Tabela 1 apresenta as palavras-chave utilizadas na pesquisa bibliográfica para o levantamento da produção científica no país, com a respectiva quantidade de artigos localizados e o seu percentual em relação ao total de artigos localizados.

Tabela 1. Palavras-chave selecionadas para o levantamento da produção científica no país e sua frequência.

\begin{tabular}{lcc}
\hline \multicolumn{1}{c}{ Palavras-chave } & $\mathrm{N}$ & $\%$ \\
\hline Deficiência intelectual & 54 & 17,9 \\
Pessoa com deficiência (PcD) & 17 & 5,6 \\
Pessoa com deficiência (PcD) e Mercado de & & \\
trabalho & 1 & 0,3 \\
Pessoa com deficiência (PcD) e Qualificação & 1 & 0,3 \\
Pessoa com deficiência mental & 1 & 0,3 \\
Retardo mental & 33 & 10,9 \\
Síndrome de Down & 195 & 64,6 \\
\hline Total & 302 & 100 \\
\hline
\end{tabular}

Os dados apresentados na Tabela 1 indicam que a maior produção científica sobre a deficiência encontra-se na palavra-chave "Síndrome de Down”, com 195 artigos científicos. Esta síndrome refere-se a um erro na deleção do cromossomo 21 e que entre as suas principais características fenotípicas esta o atraso no desenvolvimento neuropsicomotor (ADNPM), hipotonia e a deficiência intelectual.

Contudo a incidência da Síndrome de Down é de aproximadamente 1 caso para cada 700 nascimentos, cerca de 270.000 pessoas no Brasil teriam essa síndrome na população. O total de pessoas com deficiência intelectual na população brasileira é de 2.617 .025 (1,37\%), portanto, a síndrome de Down não explica o surgimento de todos os casos de pessoas com esse tipo de deficiência. Esse dado já sinaliza um viés importante na produção científica, seja pela facilidade de identificar as pessoas com esta síndrome através do exame genético do cariótipo ou pelas características fenotípicas dessa população, quer seja pela manutenção da ideia de que a deficiência intelectual tem sua origem em fatores genéticos, portanto, orgânicos. 
Na busca das palavras-chave no site da Scielo não houve limitação quanto ao período da produção científica, pois um dos propósitos foi o de levantar o total de artigos, sobre deficiência intelectual, disponíveis no referido site de busca. Após esse levantamento procedeu-se a análise da produção científica por ano em função das palavras-chave selecionadas. A Tabela 2 apresenta a distribuição da quantidade de artigos científicos localizados nas bases de dados da Scielo.

Tabela 2. Total da produção científica sobre deficiência intelectual, separadas por palavras-chave e ano de publicação.

\begin{tabular}{|c|c|c|c|c|c|c|c|c|}
\hline \multirow[b]{2}{*}{ Ano } & \multicolumn{7}{|c|}{ Palavras-chave } & \multirow[b]{2}{*}{ Total } \\
\hline & $\begin{array}{c}\text { Deficiên } \\
\text { cia } \\
\text { intelectu } \\
\text { al }\end{array}$ & $\begin{array}{l}\text { Pessoa } \\
\text { com } \\
\text { deficiên } \\
\text { cia }\end{array}$ & $\begin{array}{c}\text { PcD e } \\
\text { Mercado } \\
\text { de } \\
\text { trabalho }\end{array}$ & $\begin{array}{c}\text { PcD e } \\
\text { Qualifica } \\
\text { ção }\end{array}$ & $\begin{array}{c}\text { Pessoa } \\
\text { com } \\
\text { deficiên } \\
\text { cia } \\
\text { mental } \\
\end{array}$ & $\begin{array}{l}\text { Retardo } \\
\text { mental }\end{array}$ & $\begin{array}{l}\text { Síndro } \\
\text { me de } \\
\text { Down }\end{array}$ & \\
\hline 1993 & 0 & 0 & 0 & 0 & 0 & 0 & 1 & 1 \\
\hline 1995 & 0 & 0 & 0 & 0 & 0 & 0 & 1 & 1 \\
\hline 1997 & 0 & 0 & 0 & 0 & 0 & 1 & 1 & 2 \\
\hline 1998 & 0 & 0 & 0 & 0 & 0 & 0 & 1 & 1 \\
\hline 1999 & 0 & 0 & 0 & 0 & 0 & 0 & 3 & 3 \\
\hline 2000 & 0 & 0 & 0 & 0 & 0 & 0 & 1 & 1 \\
\hline 2001 & 0 & 0 & 0 & 0 & 0 & 1 & 0 & 1 \\
\hline 2002 & 0 & 0 & 0 & 0 & 0 & 3 & 8 & 11 \\
\hline 2003 & 0 & 0 & 0 & 0 & 0 & 1 & 9 & 10 \\
\hline 2004 & 0 & 0 & 0 & 0 & 0 & 2 & 2 & 4 \\
\hline 2005 & 0 & 0 & 0 & 1 & 0 & 1 & 5 & 7 \\
\hline 2006 & 0 & 0 & 0 & 0 & 0 & 1 & 9 & 10 \\
\hline 2007 & 1 & 1 & 0 & 0 & 0 & 3 & 16 & 21 \\
\hline 2008 & 0 & 0 & 0 & 0 & 0 & 0 & 14 & 14 \\
\hline 2009 & 0 & 0 & 0 & 0 & 0 & 3 & 12 & 15 \\
\hline 2010 & 3 & 0 & 0 & 0 & 0 & 2 & 25 & 30 \\
\hline 2011 & 3 & 2 & 0 & 0 & 0 & 6 & 15 & 26 \\
\hline 2012 & 11 & 2 & 0 & 0 & 1 & 3 & 13 & 30 \\
\hline 2013 & 7 & 1 & 0 & 0 & 0 & 2 & 14 & 24 \\
\hline 2014 & 5 & 2 & 0 & 0 & 0 & 0 & 12 & 19 \\
\hline 2015 & 10 & 4 & 0 & 0 & 0 & 3 & 13 & 30 \\
\hline 2016 & 10 & 5 & 0 & 0 & 0 & 1 & 12 & 28 \\
\hline 2017 & 4 & 0 & 1 & 0 & 0 & 0 & 8 & 13 \\
\hline Total & 54 & 17 & 1 & 1 & 1 & 33 & 195 & 302 \\
\hline
\end{tabular}


O primeiro artigo científico localizado foi publicado no ano de 1993, sendo observada uma produção modesta até o ano de 2006, com a predominância de artigos com as palavras-chave "retardo mental" e "Síndrome de Down". A partir do ano de 2007 o número de artigos científicos publicados aumenta significativamente e já se observa o início de outro perfil de produção científica, quando a pessoa com deficiência começa a ser vista não apenas como objeto de pesquisa, mas como sujeito de ação. Esse argumento se sustenta quando são observadas publicações, em quantidade expressiva, com as palavras-chave: "deficiência intelectual" e "pessoa com deficiência".

A partir do título de cada publicação e da análise dos resumos foram levantados quais aspectos relacionados à deficiência tem sido explorado no meio científico. Para tanto, foi elaborada para este estudo uma classificação dos objetivos dessas pesquisas em 18 (dezoito) categorias, apresentadas a seguir:

Genética: estudos realizados com base em experimentos genéticos ou revisão da literatura como forma de explorar e identificar os determinantes hereditários, erros de deleção cromossômica e erros inatos do metabolismo que possam explicar a etiologia genética da deficiência intelectual.

Neurodesenvolvimento: refere-se aos estudos que objetivaram o levantamento de alterações fisiológicas, encefalográficas, e do desenvolvimento das habilidades motoras, da linguagem, do raciocínio, das habilidades simbólicas e sobre a plasticidade cerebral em pessoas com deficiência intelectual. Estes estudos tiveram como base metodológica estudos de casos e delineamentos experimentais com a utilização de grupos controles (amostras) para comparações posteriores entre as médias desses grupos quanto ao desenvolvimento.

Metabolismo: esta categoria reuniu pesquisas que tiveram o objetivo de identificar e explicar alterações metabólicas e suas relações (etiologia) com a deficiência intelectual.

Aspectos do desenvolvimento clínico: artigos que exploraram por meio de estudos de casos, revisão de literatura e estudos comparativos a 
prevalência de patologias infectocontagiosas por bactérias ou fungos, características nutricionais e sobre as características relacionadas à recuperação cirúrgica de pessoas com deficiência intelectual, em especial, as pessoas com a síndrome de Down.

Práticas educacionais: essa categoria reuniu as investigações científicas com o objetivo de relatar experiências de professores com alunos com deficiência, incluindo a descrição de procedimentos pedagógicos, os processos cognitivos relativos ao desenvolvimento das habilidades matemáticas e da leitura e escrita de crianças e adolescentes.

Desenvolvimento da capacidade funcional: foram alocadas nesta categoria as produções científicas que objetivaram descrever ou comparar a capacidade funcional de pessoas com deficiência intelectual utilizando metodologia qualitativa ou quantitativa.

Relação pais e filhos ou interação social: os artigos que apresentam descrições, a partir do relato dos pais, sobre suas experiências e desdobramentos cotidianos em relação ao filho com deficiência intelectual foram agrupados nesta categoria.

Legislação: essa categoria reuniu artigos elaborados com foco em descrever os marcos históricos de leis relacionadas à $\mathrm{PcD}$, sua aplicação, sua abrangência, além das limitações e de críticas tecidas pelos autores sobre a legislação em vigor.

Avaliação: as produções científicas com o objetivo de apresentar e descrever procedimentos de avaliação diagnóstica nas áreas da medicina, psicologia e pedagógica, bem como estudos que versaram sobre a avaliação de intervenções terapêuticas, abrangendo também pesquisas de validação de instrumentos de avaliação, tais como questionários, escalas, entre outros foram contabilidades neste item.

Mobilidade: pesquisas que descrevem as possibilidades e impossibilidades de locomoção com deficiência no meio urbano.

Concepção de professores e outros profissionais sobre a PcD: nesta categoria foram alocadas as produções científicas que buscaram relatar as percepções e concepções dos profissionais das áreas da saúde e educação 
em relação à capacidade de aprendizagem, de socialização, entre outros aspectos, das pessoas com deficiência intelectual.

Serviços educacionais e outros serviços - foram agrupadas pesquisas que tiveram como objetivo descrever o funcionamento de serviços educacionais, terapêuticos e de saúde voltados para a PcD e seus familiares.

Terapias: este grupo reuniu artigos científicos que descreveram alguns procedimentos terapêuticos empregados à $\mathrm{PcD}$, tais como musicoterapia, treinamento auditivo, procedimentos odontológicos específicos para PcD, nas áreas da saúde e educação.

Pesquisas teóricas: foram alocadas neste grupo as pesquisas de cunho bibliográfico e de levantamento de produção científica sobre a $\mathrm{PcD}$.

Análise de filmes: reúne-se neste grupo artigos que descreveram a produção cinematográfica sobre a pessoa com síndrome de Down e possíveis impactos aos telespectadores.

A elaboração das categorias permitiu organizar o total de artigos localizados em função do seu objetivo, a análise do perfil da amostra analisada em terno de idade e gênero, além de permitir inferir qual o conceito central sobre deficiência que melhor representa o objetivo de cada uma dessas pesquisas, se o modelo biomédico ou o modelo social da deficiência. A Tabela 3 apresenta a classificação elaborada na presente pesquisa para os objetivos encontrados nas produções científicas com a respectiva frequência. 
Tabela 3. Levantamento das categorias de análise dos artigos com base no objetivo principal dos artigos publicado na Scielo.

\begin{tabular}{lcc}
\hline \multicolumn{1}{c}{$\begin{array}{c}\text { Principais objetivos encontrados nas pesquisas publicadas no } \\
\text { Scielo - Categorias de pesquisa }\end{array}$} & $\mathrm{N}$ & $\%$ \\
\hline Genética & 21 & $7,0 \%$ \\
Neurodesenvolvimento & 82 & $27,2 \%$ \\
Metabolismo & 12 & $4,0 \%$ \\
Aspectos do desenvolvimento clínico & 21 & $7,0 \%$ \\
Aprendizagem das habilidades escolares e práticas educacionais & 14 & $4,6 \%$ \\
Desenvolvimento da Capacidade Funcional & 11 & $3,6 \%$ \\
Habilidades sociais & 2 & $0,7 \%$ \\
Sexualidade & 5 & $1,7 \%$ \\
Autopercepção & 2 & $0,7 \%$ \\
Relação pais e filhos ou intreração social & 37 & $12,3 \%$ \\
Legislação & 4 & $1,3 \%$ \\
Mobilidade & 2 & $0,7 \%$ \\
Concepção de professores e profissionais sobre a PcD & 18 & $6,0 \%$ \\
Serviços educacionais e outros serviços & 15 & $5,0 \%$ \\
Terapias & 10 & $3,3 \%$ \\
Avaliação & 33 & $10,9 \%$ \\
Pesquisas teóricas - revisão de conceitos & 11 & $3,6 \%$ \\
Análise de filmes & 2 & $0,7 \%$ \\
\hline Total & 302 & $100,0 \%$ \\
\hline
\end{tabular}

Do total de 302 artigos publicados sobre deficiência intelectual, 136 artigos $(45,0 \%)$ investigaram aspectos relativos a possíveis causas genéticas e o desenvolvimento biológico das pessoas com deficiência. Dentre os artigos com esse perfil, foram agrupadas as categorias: Genética $(n=21)$, Neurodesenvolvimento $(n=82)$, Metabolismo $(n=12)$ e Aspectos do desenvolvimento clínico $(n=21)$. A categoria Neurodesenvolvimento foi a que apresentou a maior quantidade de artigos, dentre eles encontra-se produções científicas que se propuseram a investigar os aspectos relacionados ao desenvolvimento motor $(n=18)$, com destaque para investigações sobre a postura, tônus, marcha, equilíbrio, etc; o desenvolvimento da linguagem $(n=26)$ desde o início da verbalização, consciência fonológica, pragmática, semântica; o desenvolvimento de formas de raciocínio $(\mathrm{n}=8)$, tais como o raciocínio não verbal, raciocínio temporal, raciocínio espacial; além de das investigações que versaram sobre 
estudos referentes aos aspectos fisiológicos, encefalográficos e de plasticidade cerebral $(\mathrm{n}=30)$.

Foram contabilizados 37 artigos (12,3\%) que investigaram aspectos relativos à "Relação pais e filhos ou interação social", tais como as percepções dos pais sobre aspectos do desenvolvimento ou do comportamento dos filhos com deficiência intelectual, as relações parentais estabelecidas a partir deste diagnóstico e como os familiares percebiam as redes de apoio. Embora estes artigos se preocuparam com os aspectos relacionais entre os familiares e a PcD, notou-se a tendência dos sujeitos das pesquisas em relação às oportunidades e barreiras que a $\mathrm{PcD}$ enfrentaria, além da visão de infantilização que reveste a imagem da pessoa com deficiência intelectual.

Outros 76 artigos $(25,2 \%)$ estão relacionados às percepções de professores e outros profissionais $(n=18)$, aos serviços educacionais $(n=15)$, terapêuticos $(n=10)$ e processos de avaliação $(n=33)$, este último tanto na esfera diagnóstica, quanto na investigação científica de padrões de normalidade ou ainda relativos aos procedimentos de elaboração de instrumental avaliativo.

A realização de pesquisas que buscaram investigar os possíveis fatores biológicos, fisiológicos e genéticos causadores da deficiência intelectual $(n=136)$, somado ao percentual de pesquisas que objetivaram discutir critérios de "avaliação" diagnóstica e de pesquisa $(\mathrm{N}=33)$, os artigos que se debruçaram em realizar levantamentos bibliográficos e àqueles que apresentaram discussões teóricas sobre a deficiência $(n=11)$ e ainda, os artigos que buscaram discutir ou descrever formas e processos terapêuticos $(n=10)$; totalizaram $62,9 \%(n=190)$ dos objetivos encontrados nos artigos localizados. Esses dados ilustram claramente que a produção científica sobre a deficiência ainda se pauta, em sua grande maioria, nas concepções que fundamentam o modelo biomédico da deficiência, cujo cerne é elaborar modelos explicativos sobre o surgimento da deficiência e da investigação dos processos interventivos que objetivam a diminuição dos déficits provocados pela deficiência. 
Apenas 34 artigos $(11,3 \%)$ investigaram alguns aspectos relativos aos potenciais das pessoas com deficiência. Nesta perspectiva, o desenvolvimento da capacidade funcional $(\mathrm{n}=11)$ representa o maior percentual de artigos sobre essa perspectiva. Isso se deve ao fato da publicação da Classificação Internacional de Funcionalidade e Incapacidade (OMS, 2004), cujo objetivo central é o de auxiliar na elaboração de quadros descritivos sobre a funcionalidade do ser humano e as suas restrições, organizando essas informações dentro de um padrão reconhecimento internacionalmente. Pesquisas que consideraram a PcD como um sujeito de direito, tomando-o como um ser ativo e participativo, que pudessem, por eles mesmos, fornecer dados sobre as suas próprias percepções, a sua sexualidade e a sua capacidade de interagir com os demais, mostraram-se escassas, totalizando apenas 7 produções. Da mesma forma, ainda são escassas as produções sobre a legislação voltada à $\mathrm{PcD}$ e as condições urbanas de mobilidade para pessoas com condições sensoriais reduzidas.

Outro aspecto analisado na presente pesquisa foi à população objeto dos estudos. Nestas pesquisas foram encontrados os termos: bebê, criança, adolescente, jovem e adulto. De acordo com os critérios aplicados nos respectivos estudos, foi considerado "bebê" as pessoas com menos de 12 meses de vida. O termo "criança" identifica as pessoas na faixa etária de 1 ano até 11 anos e 11 meses de vida, "adolescente" compreende pessoas na faixa de 12 anos até 17 anos e 11 meses. O “jovem” refere-se aos indivíduos que estão na faixa etária de 18 anos até 29 anos e 11 meses; o "adulto" se estende da faixa dos 30 anos até os 60 anos. A Tabela 4 apresenta a distribuição dos artigos científicos localizados, separados pela faixa etária, aqui denominado de "tipo de população". 
Tabela 4. Total de artigos científicos sobre deficiência separados por tipo de população

\begin{tabular}{|c|c|c|c|c|}
\hline População objeto da pesquisa & $\mathrm{N}$ & $\%$ & $\begin{array}{c}\mathrm{N} \\
\text { acumulado }\end{array}$ & $\begin{array}{c}\% \\
\text { Acumulada }\end{array}$ \\
\hline Bebê & 8 & 2,6 & 8 & 2,6 \\
\hline Crianças & 102 & 33,8 & & \\
\hline Criança e Adolescente & 23 & 7,6 & & \\
\hline Criança e Jovens & 2 & 0,7 & 129 & $42,7 \%$ \\
\hline Criança e Adulto & 1 & 0,3 & & \\
\hline Crianças, jovem e adulto & 1 & 0,3 & & \\
\hline Adolescente & 7 & 2,3 & & \\
\hline Adolescente e Jovem & 1 & 0,3 & $33 *$ & $10,9 \%$ \\
\hline Adolescente e adulto & 2 & 0,7 & & \\
\hline Jovem & 12 & 4,0 & & \\
\hline Jovem e Adulto & 9 & 3,0 & $22 *$ & $7,3 \%$ \\
\hline Adulto & 31 & 10,3 & 31 & 10,3 \\
\hline Famílias & 32 & 10,6 & 32 & 10,6 \\
\hline Idoso & 1 & 0,3 & 1 & 0,3 \\
\hline Instituição ou serviço & 3 & 1,0 & 3 & 1,0 \\
\hline Revisão de literatura & 10 & 3,3 & 10 & 3,3 \\
\hline Sem especificação / artigo teórico & 57 & 18,9 & 57 & 18,9 \\
\hline Total & 302 & 100 & & 107,9 \\
\hline
\end{tabular}

*na quantidade acumulada de adolescentes foram computados 23 artigos que pesquisaram criança e adolescente. Na quantidade de pesquisa acumulada de jovens foi somado o artigo que pesquisou adolescente e jovem.

De acordo com os dados apresentados na Tabela 4, a maior concentração de pesquisas científicas sobre pessoas com deficiência considerou o tipo de população "crianças" ( $\mathrm{N}=102 ; 33,8 \%)$. Na amostra de adultos $(\mathrm{N}=31 ; 10,3 \%) 11$ pessoas foram identificadas como sendo professores ou profissionais da saúde. Nestas pesquisas o objetivo era o de investigar a compreensão destes profissionais em relação à criança com deficiência intelectual.

Do total de artigos encontrados sobre a pessoa com deficiência ( $\mathrm{N}=57 ; 18,9 \%$ ) referem-se a artigos teóricos ou de pesquisas realizados por meio da análise de prontuários médicos de hospitais escolas e de centros especializados de tratamento. Os prontuários foram selecionados a partir do CID (Código Internacional de Doenças) e das condições clínicas da 
população escolhida, sem especificar nestes artigos as idades das pessoas que tiveram os seus registros médicos selecionados para a pesquisa.

A expressiva concentração de pesquisas realizadas com amostras de crianças traz em seu bojo algumas indagações, como, o acesso do pesquisador a determinado perfil amostral para a pesquisa e, que talvez a oferta de serviços especializados reúna uma maior quantidade de pessoas, não só em função da patologia, mas também que estes sejam organizados por faixas etárias específicas. Isso faz pensar que talvez exista uma maior oferta de serviços diagnósticos, clínicos e terapêuticos voltados prioritariamente para as crianças com deficiência intelectual, em detrimento da oferta dos mesmos serviços para as pessoas que se encontram em outros estágios do desenvolvimento humano. É sabido que a oferta de serviços especializados de estimulação sensório-motora logo no primeiro ano de vida da pessoa com deficiência impacta positivamente em seu desenvolvimento, inclusive, diminuindo déficits esperados em função da patologia. Mas isso não significa que as pessoas com deficiências não necessitem de suporte terapêutico ao longo de sua vida.

Contudo, a provável redução de vagas em serviços especializados para pessoas que entraram na adolescência ou se encontram na vida adulta pode indicar uma opção destes serviços por determinado público-alvo, redução muitas vezes geradas por cortes ou ausências de verbas públicas, além do perfil dos profissionais envolvidos. Essa hipótese, por sua vez, pode indicar que a pessoa com deficiência intelectual, a partir de certa idade, passa a sofrer a chamada "invisibilidade social" dentro dos serviços de saúde especializados e consequentemente, se torna pouco acessível para as pesquisas científicas.

Desta forma, a redução significativa de pesquisas com pessoas com deficiência em idades para além da infância pode indicar pouco acesso do pesquisador a estas pessoas. No entanto, deve-se considerar que estas pessoas estão inseridas em algum outro contexto, quer seja educacional, social ou familiar, além das instituições de saúde. Estes outros espaços podem constituir igualmente em oportunidades de realização de pesquisas, 
principalmente as investigações científicas que priorizem outros aspectos da vida humana, além das variáveis e dos interesses que caracterizam o modelo biomédico ou o modelo social da deficiência.

E é justamente neste sentido que outras indagações surgem em relação ao número reduzido de pesquisas encontradas sobre as pessoas deficientes com mais de 11 anos de idade. Essas indagações recaem sobre o interesse dos pesquisadores em relação aos objetivos de suas pesquisas. $\mathrm{O}$ que pode estar acontecendo? Trata-se de resistência à realização de pesquisa impostas por outros espaços de convívio humano que dificultam o acesso do pesquisador aos sujeitos de pesquisa? Indica a preferência dos pesquisadores em investigar prioritariamente alguns aspectos da infância da pessoa com deficiência em detrimento de outros? Essa indagação suscita outro questionamento: Será que ainda existe dificuldade das diversas áreas do conhecimento científico em reconhecer a pessoa com deficiência intelectual como um sujeito de direito com muitos outros aspectos e facetas a serem explorados, além das condições biológicas, genéticas e do desenvolvimento do seu organismo?

Evidentemente que esses questionamentos abrem possibilidade de novas pesquisas. Entretanto, neste momento, o que é possível constatar de fato é que existe uma visível segregação das pessoas com deficiência intelectual maiores de 11 anos no campo da pesquisa. Isso equivale a dizer que existe uma exclusão social da pessoa com deficiência no campo científico. E quando estas pessoas são reconhecidas no campo investigativo da ciência, são vistas como objetos de pesquisa e poucas vezes como sujeitos, fato que indica que estes não são totalmente incluídos. Sua inserção na investigação científica ainda é permeada por segregação, pois apenas parte do sujeito é considerado, é analisado e explorado a partir do modelo biomédico, onde neste cenário o sujeito quase não possui voz ativa.

Também foi realizada uma análise dos principais objetivos de pesquisa em função da amostra selecionada. Neste cruzamento de dados foi possível verificar que na maior parte dos objetivos identificados neste mapeamento a amostra de sujeitos pesquisados foi prioritariamente o de 
crianças, exceto nos objetivos denominados de "Mobilidade", "sexualidade", "autopercepção", "revisão da literatura" e "legislação". As pesquisas realizadas com o objetivo intitulado "relação pais e interação" buscaram entrevistar alguns pais de crianças com deficiências para obterem dados sobre a interação entre os membros da família, a partir das dificuldades que estes encontravam para lidar com as deficiências de seus filhos. Nestas pesquisas, a criança também compôs as amostras de pesquisas de forma indireta, uma vez que a interação dos adultos com elas constituiu o objetivo de pesquisa.

De acordo com Diniz (2007) é premente a necessidade de ampliação do leque de pesquisas que abordem os diversos aspectos relacionados à pessoa com deficiência. Principalmente, há carência de estudos que considerem a PcD como integrante da sociedade, sujeito pleno e ativo e detentor de direitos tal como postulado na definição de deficiência pelo modelo social. A predominância de pesquisas com crianças deficientes já traz alguns questionamentos quanto às percepções dos pesquisadores sobre o reconhecimento da existência de adolescentes, de jovens, de adultos e de idosos deficientes, além da aparente falta de reconhecimento destas pessoas quanto ao seu direito à uma participação ativa

O objetivo central desta pesquisa foi o de investigar a produção científica disponível na plataforma Scielo sobre a pessoa com deficiência intelectual em função do arcabouço teórico relativo à concepção sobre a pessoa com deficiência. Para esta análise foi considerado o modelo biomédico da deficiência e o modelo social da deficiência. A primeira concepção teórica, biomédica, tem por finalidade a realização de pesquisas de mapeamento e de investigação de etiologias que possam explicar o surgimento de pessoas com deficiência. Já o segundo modelo conceitual, construído a partir da perspectiva histórico-cultural, traz a ideia de que a existência da deficiência está nas barreiras sociais e atitudinais, impostas pela sociedade as pessoas com deficiência.

A presente pesquisa permitiu verificar a tendência nas pesquisas brasileiras em relação aos dois paradigmas sobre o tema em pauta. A partir 
da análise apresentada na Tabela 3 e da leitura dos resumos dos referidos artigos localizados foi possível inferir qual o modelo teórico sobre a deficiência norteou as pesquisas. Embora ambos os modelos conceituais tenham surgido na década de 60 do século XX, é notória a forte influência do modelo biomédico influenciando as pesquisas nacionais sobre a deficiência intelectual, conforme demonstrada na Tabela 5.

Uma das possíveis explicações para a tamanha discrepância teóricoconceitual que embasam as pesquisas neste campo, é a de que as pesquisas realizadas no modelo biomédico são predominantemente realizadas por pesquisadores representantes dos centros de pesquisas da área da saúde, enquanto que o modelo social da deficiência seria objeto de estudo de pesquisadores representantes das áreas das humanidades.

Em função das áreas de pesquisas envolvidas, nota-se a predominância de pesquisas elaboradas a partir de métodos quantitativos, com o forte emprego de modelos estatísticos que auxiliam na inferência e na interpretação desses resultados. Já na área das humanidades, o predomínio de modelos investigativos qualitativos pode tornar as pesquisas mais morosas, uma vez que as análises seguem critérios específicos que demandam um tempo considerável para a sua completa realização. 
Tabela 5. Análise da produção científica sobre deficiência intelectual, separada em função da possível classificação de seus objetivos em relação ao modelo conceitual de deficiência.

\begin{tabular}{|c|c|c|c|c|}
\hline $\begin{array}{l}\text { Modelo } \\
\text { Teórico }\end{array}$ & Categorias de pesquisa & $\mathrm{N}$ & Total & $\%$ \\
\hline \multirow{10}{*}{$\begin{array}{l}\text { Modelo } \\
\text { Biomédico }\end{array}$} & Genética & 21 & \multirow{10}{*}{256} & \multirow{10}{*}{$84,8 \%$} \\
\hline & Neurodesenvolvimento & 82 & & \\
\hline & Metabolismo & 12 & & \\
\hline & Aspectos do desenvolvimento clínico & 21 & & \\
\hline & $\begin{array}{l}\text { Aprend. das habilid. escolares e práticas } \\
\text { educacionais }\end{array}$ & 14 & & \\
\hline & Relação pais e filhos ou interação social & 37 & & \\
\hline & Serviços educacionais e outros serviços & 15 & & \\
\hline & Terapias & 10 & & \\
\hline & Avaliação & 33 & & \\
\hline & Pesquisas teóricas - revisão de conceitos & 11 & & \\
\hline \multirow{7}{*}{$\begin{array}{l}\text { Modelo } \\
\text { social da } \\
\text { deficiência }\end{array}$} & Desenvolvimento da Capacidade Funcional & 11 & \multirow{7}{*}{46} & \multirow{7}{*}{$15,2 \%$} \\
\hline & Habilidades sociais & 2 & & \\
\hline & Sexualidade & 5 & & \\
\hline & Autopercepção & 2 & & \\
\hline & Legislação & 4 & & \\
\hline & Análise de filmes & 2 & & \\
\hline & $\begin{array}{l}\text { Mobilidade } \\
\text { Concepção de professores e profissionais } \\
\text { sobre a PcD }\end{array}$ & $\begin{array}{l}2 \\
18\end{array}$ & & \\
\hline Total & & 302 & 302 & $100 \%$ \\
\hline
\end{tabular}

Outros fatores importantes precisam ser considerados nesta breve discussão. Um deles diz respeito às possibilidades de financiamento das pesquisas, por parte dos laboratórios farmacêuticos, aos estudos delineados pelos centros de pesquisas das áreas da saúde. Enquanto que as pesquisas elaboradas nas áreas das humanidades podem contar apenas com o financiamento das agências de fomento, cujo montante monetário a ser investido nesta área da produção acadêmica nem sempre consegue atingir satisfatoriamente um volume significativo de projetos enviados para análise.

$\mathrm{O}$ acesso ao público com deficiência também se constitui um desafio adicional para os pesquisadores desse público no campo das humanidades. Uma vez que a predominância de serviços de atendimento especializado são ofertados pela área da saúde, estes acabam por reunir um número significativo de pessoas com este perfil, facilitando o acesso aos 
pesquisadores da área da médica que se encontram nestas unidades. Com a lei de inclusão, muitas crianças e adolescentes encontram-se matriculados na rede regular de ensino, mas a dificuldade encontrada pelos pesquisadores para realizar seus estudos nas unidades educacionais de ensino, pode ser considerado um quesito negativo para a realização de investigações científicas para além dos moldes culturalmente impostos pela área da saúde.

Essas hipóteses levam a um último questionamento, sem esgotar outras reflexões sobre o assunto. Talvez já exista no meio científico muitos pesquisadores desejosos em realizar pesquisas na área da deficiência, tomando como referencial teórico para a compreensão deste fenômeno, o modelo social da deficiência. Contudo, a dificuldade de acesso às pessoas com deficiência intelectual, somada à aparente escassez de verbas para financiamento das pesquisas com este delineamento conceitual, são fatores que devem ser considerados, além do aparente desinteresse por parte dos pesquisadores de realizarem seus estudos nesta perspectiva de análise histórico-cultural.

\section{Considerações Finais}

O presente estudo de caráter documental evidenciou a carência de pesquisas na área das ciências sociais no tocante a deficiência intelectual. Foram levantadas algumas hipóteses para explicar, inicialmente, os resultados encontrados. Contudo, sugere-se que outros levantamentos sejam realizados a partir de outras palavras-chave com o objetivo de ampliar o leque de análise sobre a pessoa com deficiência intelectual, com vistas à construção de dados mais sólidos que permitam sustentar ou refutar as hipóteses levantadas.

Existe de fato uma preocupação em relação aos dados levantados nesta pesquisa, a consolidação do modelo biomédico da deficiência, em detrimento do modelo social da deficiência no imaginário social. A maior parte das pesquisas localizadas se debruçou em investigar e explicar os meandros da gênese da deficiência intelectual e das limitações da pessoa 
deficiente. Esses dados, embora relevantes, fornecem e perpetuam a ideia da deficiência a partir de falhas ocorridas no organismo humano ou mesmo em decorrência a um trauma ou lesão sofrida pelo sujeito.

Essa visão da deficiência, quando não complementada por uma concepção social, o que se nota devido ao baixo número de pesquisas na área das humanidades, pode interpor barreiras para uma efetiva mudança paradigmática da sociedade em relação à pessoa com deficiência. Embora sejam importantes as pesquisas sobre a deficiência realizadas na perspectiva biomédica, a ausência de pesquisas na área das humanidades, na perspectiva do modelo social da deficiência, pode contribuir para reforçar os estigmas sociais que alimentam os processos de exclusão nos mais diferentes setores da sociedade.

\section{Referências}

American Psychiatry Association. Manual diagnóstico e estatístico de transtornos mentais. DSM-5. Porto Alegre: Artmed. 2013. 976 p.

ANTIPOFF, Daniel I. A orientação profissional para excepcionais infra-dotados. In: Amae educando, Instituto de Educação de Minas Gerais, n 136-ago, ano XIV, 1981.

BAMPI, Luciana Neves da Silva; GUILHEM, Dirce; ALVES, Elioenai Dornelles. Modelo social: uma nova abordagem para o tema deficiência. Rev. LatinoAm. Enfermagem, Ribeirão Preto , v. 18, n. 4, p. 816823, Aug. 2010. Disponível em: http://www.scielo.br/scielo.php?script=sci_arttext\&pid=S0104$11692010000400022 \& \operatorname{lng}=$ en\&nrm=iso. Acesso em: 12 dez. 2017. http://dx.doi.org/10.1590/S0104-11692010000400022.

BRASIL. Palácio do Planalto. Lei no 13146, de 6 de julho de 2015. Institui a Lei Brasileira de Inclusão da Pessoa com Deficiência (Estatuto da Pessoa com 
Deficiência). Brasília, DF: Palácio do Planalto, 2015. Disponível em: http://www.planalto.gov.br/ccivil 03/ ato2015-2018/2015/lei/113146.htm Acesso em: 12 dez. 2017.

BRASIL. Palácio do Planalto. Decreto no 6.949, de 25 de agosto de 2009. Promulga a Convenção Internacional sobre os Direitos das Pessoas com Deficiência e seu Protocolo Facultativo, assinados em Nova York, em 30 de março de 2007. Brasília, DF: Palácio do Planalto, 2009. Disponível em: http://www.planalto.gov.br/ccivil 03/ ato20072010/2009/decreto/d6949.htm acesso em: 12 dez. 2017.

DIAS, Sueli de Souza; OLIVEIRA, Maria Cláudia Santos Lopes de. Deficiência intelectual na perspectiva histórico-cultural: contribuições ao estudo do desenvolvimento adulto. Rev. bras. educ. espec., Marília , v. 19, n. 2, p. 169-

182, June 2013. Disponível em: http://www.scielo.br/scielo.php?script=sci_arttext\&pid=S141365382013000200003\&lng=en\&nrm=iso. Acesso em: 17 dez. 2017. http://dx.doi.org/10.1590/S1413-65382013000200003.

DINIZ, Débora. O que é deficiência. São Paulo: Editora Brasiliense, 2007.

FRANÇA, Tiago Henrique. Modelo social da deficiência: uma ferramenta sociológica para a emancipação social. Lutas Sociais, São Paulo, vol.17, n.31, p.59-73. jul/dez. 2013. Disponível em: https://revistas.pucsp.br/index.php/ls/issue/view/1313/showToc acesso em: 17 dez. 2017.

GESSER, M.; NUERNBERG, A. H.; Toneli, M. J. F. A contribuição do Modelo Social da Deficiência à Psicologia Social. Psicologia \& Sociedade, v.24, n.3, p.557566. 2012. Disponível em: http://www.scielo.br/pdf/psoc/v24n3/09.pdf Acesso em: 12 dez. 2017. 
GOMES, Ruthie Bonan; LHULLIER, Cristina. Representação social da deficiência intelectual na relação entre psicologia e educação. Psicol. educ., São Paulo, n. 44, p. 93-102, jun. 2017. Disponível em:

http://pepsic.bvsalud.org/scielo.php? script=sci arttext\&pid=S141469752017000100009\&lng=pt\&nrm=iso. Acesso

em: 17 dez. 2017. http://dx.doi.org/10.5935/2175-3520.20170009.

IBGE. Instituto Brasileiro de Geografia e Estatística. CENSO Demográfico. Características gerais da população, religião e pessoas com deficiência. 2010. Disponível em: https://censo2010.ibge.gov.br/resultados.html Acesso em 12 dez. 2017.

OMS - Organização Mundial da saúde. Classificação internacional de funcionalidade, incapacidade e saúde. Lisboa, 2004.

PESSOTTI, I. Deficiência mental: da superstição à ciência. Marília: ABPEE, 2012.

SCHALOCK, R. L., BORTHWICK-DUFFY, S. A., BRADLEY, V. J., BUNTINX, W. H. E., COULTER, D. L., CRAIG, E. M., et al. Intellectual disability: definition, classification, and systems of supports Washington, DC: American Association on Intellectual and developmental disabilities, 2010.

WERNECK, Claudia. Modelo médico x modelo social da deficiência. Em: Manual da mídia legal. Rio de Janeiro: WVA Editora, 2004.

Submetido em: 15/01/2018

Aceito em: $20 / 05 / 2018$

Publicado em: 15/10/2018 